\title{
Using video playbacks to study visual communication in a marine fish, Salaria pavo
}

\author{
DAVID M. GONÇALVES*, RUI F. OLIVEIRA*, KAY KÖRNER†, JENS R. POSCHADEL† \& INGO SCHLUPP† \\ *Unidade de Investigação em Eco-Etologia, Instituto Superior de Psicologia Aplicada, Lisboa \\ $\nmid$ Zoologisches Institut und Zoologisches Museum der Universität Hamburg
}

(Received 26 October 1999; initial acceptance 18 January 2000;

final acceptance 7 April 2000; MS. number: 6389)

\begin{abstract}
Video playbacks have been successfully applied to the study of visual communication in several groups of animals. However, this technique is controversial as video monitors are designed with the human visual system in mind. Differences between the visual capabilities of humans and other animals will lead to perceptually different interpretations of video images. We simultaneously presented males and females of the peacock blenny, Salaria pavo, with a live conspecific male and an online video image of the same individual. Video images failed to elicit appropriate responses. Males were aggressive towards the live male but not towards video images of the same male. Similarly, females courted only the live male and spent more time near this stimulus. In contrast, females of the gynogenetic poecilid Poecilia formosa showed an equal preference for a live and video image of a $P$. mexicana male, suggesting a response to live animals as strong as to video images. We discuss differences between the species that may explain their opposite reaction to video images.
\end{abstract}

(ㄷ) 2000 The Association for the Study of Animal Behaviour

Playbacks have been widely used in the study of animal communication. They are potentially the most powerful experimental tool available to investigate the significance of animal signals (McGregor et al. 1991). Audio playbacks have been successfully applied to the study of acoustic communication for more than 50 years (Falls 1991) and issues such as female mate choice and species recognition (e.g. Myrberg et al. 1986) or individual recognition (e.g. Myrberg \& Riggio 1985) have been addressed with this technique.

Video playback methods have recently become popular because of developments in video and computer technology. Experimental set-ups in which the video playback technique is used instead of a live stimulus have many advantages: it allows the manipulation of a single variable in the stimulus (e.g. size, behaviour) while controlling for all others; it eliminates variation in motivation, physical appearance or effects of experience of the stimulus individuals; from an ethical standpoint, fewer manipulated animals can be used or predators can be simulated; and chimera stimuli can be created (e.g. a female with male-like behaviour; Kodric-Brown \&

Correspondence: D. M. Gonçalves, Unidade de Investigação em Eco-Etologia, Instituto Superior de Psicologia Aplicada, Rua Jardim do Tabaco 34, 1149-041 Lisboa, Portugal (email: davidg@ispa.pt). K. Körner, J. R. Poschadel and I. Schlupp are at the Zoologisches Institut und Zoologisches Museum der Universität Hamburg, Martin Luther King Platz 3, D-20146 Hamburg, Germany.

0003-3472/00/090351+07\$35.00/0
Nicoletto 1997; D'Eath 1998; Körner et al. 1999; Landmann et al. 1999).

This technique is controversial, however (D'Eath 1998; Fleishman et al. 1998) and has produced conflicting results. Successful experiments have been conducted on several groups of animals including spiders (e.g. Clark \& Uetz 1990), birds (e.g. Evans \& Marler 1992), reptiles (e.g. Macedonia \& Stamps 1994) and fish (e.g. Rosenthal et al. 1996; Körner \& Parzefall 1997; Balshine-Earn \& Lotem 1998, but see D'Eath 1998 for a discussion of the interpretation of these results). Reported failures of video playbacks include studies by Pepperberg (1994) and Pepperberg et al. (1998) in grey parrots, Psittacus erithacus, Ryan \& Lea (1994) in pigeons, Columba livia, and D'Eath \& Dawkins (1996) and Patterson-Kane et al. (1997) in domestic chickens, Gallus gallus domesticus. Negative responses to video images, however, may be more widespread than reflected in the literature, owing to publication bias.

As far as we know, all published studies in which video playbacks were applied to fish have been successful, although so far only freshwater species have been tested (see D'Eath 1998 for a review). This technique is potentially useful for the study of marine fish because in many of these species visual communication plays a major role in social interactions and their social behaviour is well known.

We tested the application of video playbacks to a marine intertidal fish species with a rich visual 
communication system, the peacock blenny, Salaria pavo. This species has an accentuated sexual dimorphism and dichromatism: males are larger and have a well-developed head crest, a dark brown eye spot behind the eye and the first two rays of the anal fin modified into an anal gland that produces a pheromone used for female attraction (Fishelson 1963; Laumen et al. 1974; Papaconstantinou 1979; Patzner et al. 1986; Patzner \& Seiwald 1987; Zeeck \& Ide 1996). Both sexes display a distinct nuptial coloration during courtship (Fishelson 1963; Patzner et al. 1986; Abel 1993). In a Portuguese population from the Algarve sex role reversal of courtship behaviour occurs, with females being the active courting sex induced by the scarcity of nesting sites (Almada et al. 1994, 1995). In other populations of $S$. pavo in which nesting substrates are abundant, males are the active sex during courtship (i.e. Mediterranean, Fishelson 1963; Patzner et al. 1986). In the Portuguese population males occur as two distinct sexually active morphs: nest-holding males that actively defend nests and guard eggs and sneaker males that mimic the appearance and behaviour of females in order to try to approach a nest and sneak fertilizations (Ruchon et al. 1995; Gonçalves et al. 1996). This mating system offers a wide array of questions to study that could be addressed using video playbacks, such as the role of male secondary sex characters in female mate choice, the role of female characteristics in male mate choice and the role of secondary sex characters on the female mimicry of sneaker males.

We evaluated the reactions of male and female $S$. pavo to live and video images of a conspecific nesting male and compared them with those of a freshwater species already known to react to video images, the gynogenetic Amazon molly, Poecilia formosa (Körner et al. 1999; Landmann et al. 1999). Females of this species were tested with live and video images of a Poecilia mexicana sperm donor male. We compared the reactions of these species to four simultaneous presentations of stimuli: (1) live fish versus filmed fish; (2) real background versus filmed background; (3) live fish versus filmed background; and (4) real background versus filmed fish.

If the fish reacted to live and video stimuli in the same way, the reactions to the stimuli in treatments 3 and 4 , but not those in 1 and 2 , should differ. If the fish reacted more strongly to the live stimulus than to the filmed one, we predicted a difference in treatments 1, 3 and 4 but not in treatment 2 . Finally, if they did not respond to video images a difference in treatments 1 and 3 , but not in treatments 2 and 4, was predicted.

\section{METHODS}

\section{Fish}

\section{Salaria pavo}

All individuals of S. pavo were collected at the Ria Formosa Nature Park (Algarve, Portugal; 36 ${ }^{\circ} 59^{\prime} \mathrm{N}, 7^{\circ} 51^{\prime} \mathrm{W}$ ) and kept under standard conditions in the laboratory for at least 1 month before the experiments. The fish were measured and individually marked by dorsal or anal fin ray clipping. The sexes were kept separately in groups of
6-12 individuals maintained in tanks of $70 \times 35 \mathrm{~cm}$ and $40 \mathrm{~cm}$ high (98 litres) with a layer of coral sand and provided with abundant shelters. Natural photoperiod was supplied by a fluorescent light (15W) and salinity remained constant at 35\%. The fish were kept at room temperature $\left(20 \pm 2^{\circ} \mathrm{C}\right)$ and fed daily with common cockles (Cerastoderma spp.) and occasionally with live marine invertebrates. We conducted the experiments during the breeding season of the species. We used 26 sexually active males and six females.

\section{Poecilia formosa}

Poecilia formosa is an all-female, gynogenetic fish in which sperm of $P$. mexicana or $P$. latipinna males serve to trigger embryogenesis and normally no genetic material from the sperm donor male is transmitted to the offspring (for a description of the system see Schlupp et al. 1998). In nature, it may occur in fresh or brackish waters, although in captivity it may be kept in sea water. We used individuals that originated from randomly outbred laboratory strains mantained in the Zoological Institute of Hamburg University (for details see Schlupp et al. 1991). In Lisbon, where the experiments took place, the fish were kept individually in tanks of $15 \times 7 \mathrm{~cm}$ and $8 \mathrm{~cm}$ high (8 litres). The tanks were mantained at $25 \pm 1^{\circ} \mathrm{C}$ under a 14:10 h light:dark photoperiod. The fish were measured prior to the experiments and fed daily with commercial flake food. They were gradually acclimated to a salinity of $35 \%$. This has no negative effects in this species (I. Schlupp, personal observation). We used 20 female $P$. formosa and two male $P$. mexicana.

\section{Experimental Set-up}

In all experiments we tested each fish in four choice situations.

\section{Treatment 1: live fish versus filmed fish}

The test fish were simultaneously presented with a live fish and online video images of the same individual (filmed fish). At one end of the test tank $(60 \times 30 \mathrm{~cm}$ and $30 \mathrm{~cm}$ high) was the live stimulus tank $(35 \times 20 \mathrm{~cm}$ and $25 \mathrm{~cm}$ high) and at the other a Sony PVM-9044QM monitor (Fig. 1). The monitor was connected by an S-VHS cable to a Sony Hi8 CCD TR3100R camcorder that was placed in front of the other side of the live stimulus tank.

The test tank was separated from the two stimuli by one-way mirrors placed outside the tank, which ensured that the test animals could see the live stimulus and the video stimulus but that the fish used as the live stimulus could not see the test fish. Another one-way mirror was placed between the live stimulus tank and the video camera to ensure that the orientation of the live stimulus was random. In this way the test animal was simultaneously presented with the same individual, live and filmed. Both the test tank and the live stimulus tank had a $5-\mathrm{cm}$ layer of coral sand and were lined with light brown cardboard to minimize reflections. At each end of the experimental tank there was an opening in the cardboard $(16 \times 12 \mathrm{~cm}$, equal to the monitor size) 


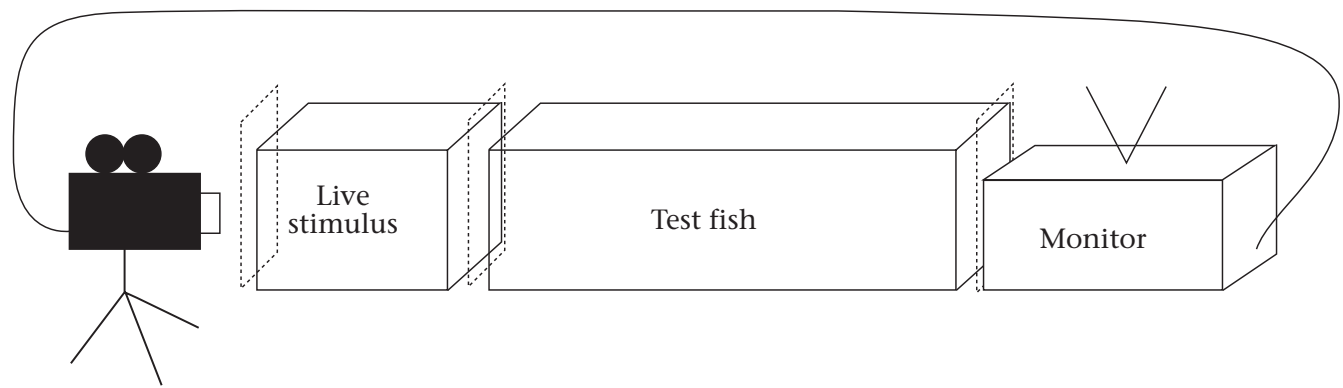

Figure 1. The experimental set-up used in treatments 1 and 2 . The test tank was flanked at one end by the live stimulus tank and at the other by a video monitor which was connected to a camcorder placed in front of the other side of the live stimulus tank. The test animal was thus presented simultaneously with the same stimulus, one live and one filmed. In treatments 3 and 4 a third tank, identical to the live stimulus tank, was filmed. Dashed line: one-way mirrors.

through which test fish could see both stimuli. The camera focal length was adjusted so that the size of the stimulus fish on the monitor was life size or smaller (as the fish swam away from the camera). The camera was positioned so that the filmed area roughly matched the area visible from the test tank through the opening in the cardboard. Vertical lines drawn on the front and back walls of the test tank divided it into three equal sections, one neutral (central) and two preference zones adjacent to each stimulus. Soft illumination was provided by a $15-\mathrm{W}$ fluorescent light covered partly with black cardboard. The live stimulus tank was illuminated by two $15-\mathrm{W}$ fluorescent lights. The monitor was placed side by side with the live stimulus tank and its brightness adjusted by eye to match the live stimulus tank brightness. Fish used as stimuli were acclimated to the tank for 1 day.

When the fish used as a stimulus was an S. pavo male (experiments 1 and 2), a nest was placed in the live stimulus tank, opening on to the centre of the tank. The males used as stimuli typically spent most of the time inside the nest with the head out in an area visible to the test animals. When the fish used as a stimulus was a P. mexicana male (experiment 3) a glass partition restricted the male to an area visible to the test fish. In this case both tanks were not at room temperature $\left(20 \pm 2^{\circ} \mathrm{C}\right)$ as with $S$. pavo, but were kept at $25 \pm 1^{\circ} \mathrm{C}$.

Treatment 2: real background versus filmed background

The test fish were simultaneously presented with an empty tank (real background) and online video images of the same empty tank (filmed background). The set-up was similar to the one described above. This control ensured that fish were not reacting to features of the monitor or of the live stimulus tank itself.

\section{Treatment 3: live fish versus filmed background}

The test fish were simultaneously presented with a live fish and video images of an empty tank. In this set of trials a third empty tank, identical to the live stimulus tank, was filmed.

\section{Treatment 4: real background versus filmed fish}

The test fish were simultaneously presented with an empty tank and images of a fish. The set-up was similar to the one described above, with the filmed fish being kept in the third tank.

\section{Experiment 1: S. pavo Males with Conspecific Male}

In the first experiment 24 male $S$. pavo (standard length, SL: $\bar{X} \pm \mathrm{SE}=9.7 \pm 0.3 \mathrm{~cm}$, range $7.6-12.2$ ) were tested with the same conspecific male as stimulus (SL $13.2 \mathrm{~cm})$. We recorded the time spent in each of the preference zones, the time spent in agonistic display in which the fish raised the caudal, anal and dorsal fins, and the number of bites directed at the stimulus (see Fishelson 1963 for a detailed description of these behaviours). Previous observations showed that males display aggressively to another conspecific male within the first few minutes of visual contact (unpublished data). Trials lasted $10 \mathrm{~min}$ and started as soon as the test fish was released with a hand net in the neutral zone.

\section{Experiment 2: S. pavo Females with Conspecific Male}

Six female $S$. pavo (SL: $\bar{X} \pm \mathrm{SE}=7.1 \pm 0.6 \mathrm{~cm}$, range 5.3 9.1) were tested with the same conspecific male (SL $11.4 \mathrm{~cm}$ ) as stimulus. Since females may start courting a conspecific male only after several minutes of visual contact (unpublished data) observations were conducted for $20 \mathrm{~min}$. Females court males by quickly flickering the pectoral fins simultaneously, while opening and closing the mouth in synchrony. During courtship, females usually display their nuptial coloration, which consists of a striped pattern of alternated vertical dark and light bands on the head and body (Fishelson 1963; Patzner et al. 1986). We measured the time spent in each of the preference zones, the number of times the nuptial coloration was displayed and the number of courtship displays directed at each stimulus. To ensure that test females were sexually receptive, we administered an intraperitoneal injection of $150 \mu \mathrm{l}$ saline containing $9 \mu \mathrm{g}$ des-Gly10, [D-Ala6]-luteinizing hormone releasing hormone ethylamide (Sigma, Lisbon, Portugal) $48 \mathrm{~h}$ prior to females being tested. On the first day of the experiment females were placed in a small tank $(35 \times 20 \mathrm{~cm}$ and $25 \mathrm{~cm}$ high) with a nesting male and we recorded their 
behaviour for $10 \mathrm{~min}$. Only females that courted the male were subsequently used in the experiments. The experimental procedure was otherwise the same as in experiment 1 .

\section{Experiment 3: P. formosa Females with $P$. mexicana Male}

Twenty female $P$. formosa (SL: $\bar{X} \pm \mathrm{SE}=3.4 \pm 0.05 \mathrm{~cm}$, range 3.1-4.0) were tested and two male $P$. mexicana (SL $4.5 \mathrm{~cm}$ ) were used as stimuli. Ten females were tested with each of the males. We measured only the time spent in each of the preference zones. Kodric-Brown (1992) showed for Poecilia reticulata that time spent near the male is a good predictor of female mate choice in visual trials. The experimental procedure was otherwise the same as in experiment 1 .

In all experiments the order of the treatments was randomized and side preferences were controlled by switching the side of the live stimuli tank and of the monitor. Position in the aquaria and behavioural responses were recorded with a Psion organizer and data were imported to the Observer PC Software (Noldus Information Technology, Wageningen, The Netherlands).

Unless noted otherwise statistical analysis was performed with Wilcoxon signed-ranks tests. All statistical tests are two tailed.

\section{Ethical Note}

Poecilia spp. were transported from Hamburg to Lisbon as hand luggage in three dark plastic containers (ca. 5 litres each). The blennies were transported from the Algarve to Lisbon in two containers (ca. 50 litres each). In both cases aeration was supplied by portable air pumps. No animal died during transport or captivity and they all remained healthy throughout the study. The collection of the blennies was authorized by the Ria Formosa Nature Park Direction. The fin ray clipping technique used to mark $S$. pavo is a common marking technique in fish. We have had in our laboratory $S$. pavo individuals marked with this technique for several months and no adverse effects were recorded. The fin rays regenerate completely after a few months and we never observed infections in the clipped area. The most intense agonistic behaviour of male S. pavo consisted of bites, in which the fish tried to bite the aquarium glass close to the stimuli. No adverse effect on the fish was recorded from this or any other agonistic behaviour. The hormone injections were licensed by the Portuguese Veterinary Council (Direcção Geral de Veterinária). All S.pavo individuals were released in good condition in the same place where they were captured. As the Poecilia spp. individuals originated from laboratory outbred strains they were kept in the laboratory after the experiments.

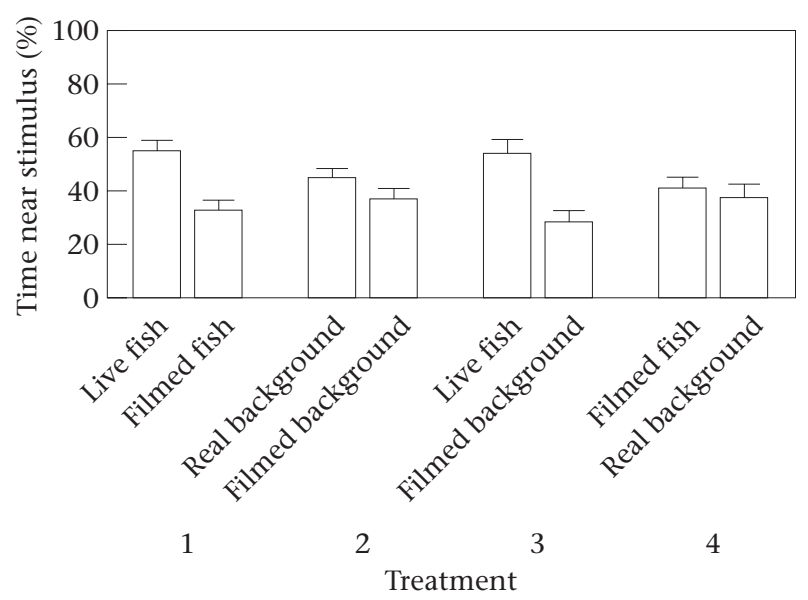

Figure 2. Mean $+S E$ time spent by $S$. pavo males near each stimulus. Treatment 1: $Z=2.60, N=24, P=0.009$; treatment $2: Z=1.20, N=24$, $P=0.230$; treatment $3: Z=2.51, N=24, P=0.012$; treatment 4 : $Z=0.29, N=24, P=0.775$.

\section{RESULTS}

\section{Experiment 1: S. pavo Males with Conspecific Male}

Male S. pavo always spent more time near the live conspecific stimuli (Fig. 2, treatments 1 and 3). These differences cannot be explained by a preference for some other feature of the live stimulus tank over the video monitor (Fig. 2, treatment 2). When video images of the male were displayed against an empty tank no difference in time spent near the stimulus was recorded (Fig. 2, treatment 4). In the absence of the live male no agonistic behaviours were recorded (treatments 2 and 4). Bites were directed exclusively at the live male and the fish spent more time in agonistic display in front of the live male (Table 1).

\section{Experiment 2: S. pavo Females with Conspecific Male}

Female $S$. pavo always spent more time near the live male. This difference was almost significant in treatment 1 (live fish versus filmed fish) and significant in treatment 3 (live fish versus filmed background; Fig. 3). No difference in time spent near the stimulus was recorded in treatment 4 (filmed fish versus real background), suggesting that females did not perceive the filmed stimulus (Fig. 3). Only live males were courted. Three of the six females courted the live male either in treatment 1 or 3 and four displayed nuptial coloration when they were in the preference zone adjacent to the live stimuli.

\section{Experiment 3: $P$. formosa Females with P. mexicana Male}

Our results confirmed previous studies with $P$. formosa. Females spent more time near the male stimulus, either live or filmed when this was tested against a filmed or real 
Table 1. Agonistic behaviours $(\bar{X} \pm \mathrm{SE})$ directed at live or filmed stimuli by male S. pavo (experiment 1 )

\begin{tabular}{|lcc|}
\hline & $\begin{array}{c}\text { Number } \\
\text { of bites }\end{array}$ & $\begin{array}{c}\text { Time spent in } \\
\text { agonistic display (\%) }\end{array}$ \\
\hline $\begin{array}{l}\text { Treatment } 1 \\
\text { Live fish } \\
\text { Versus } \\
\text { Filmed fish }\end{array}$ & $0.63 \pm 0.39$ & $2.66 \pm 0.84$ \\
$\begin{array}{l}\text { Treatment } 3 \\
\text { Live fish } \\
\text { Versus } \\
\text { Filmed background }\end{array}$ & $0.67 \pm 0.36$ & $0.01 \pm 0.04$ \\
\hline
\end{tabular}

Bites: treatment 1: $Z=1.83, N=24, P=0.068$; treatment $3: Z=2.02$, $N=24, P=0.043$; agonistic display: treatment $1: Z=2.51, N=24$, $P=0.012$; treatment 3: $Z=0.29, N=24, P=0.775$. In treatments 2 and 4 no agonistic behaviours were recorded.

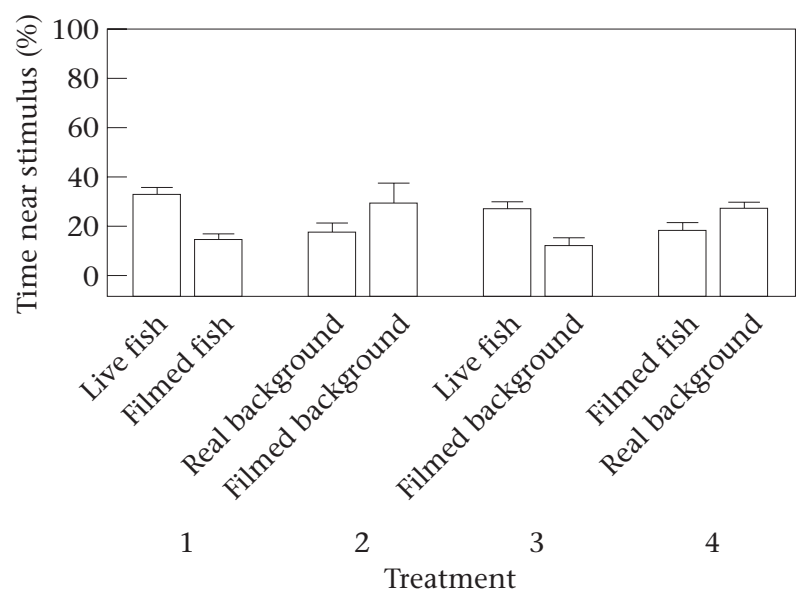

Figure 3. Mean $+\mathrm{SE}$ time spent by $S$. pavo females near each stimulus. Treatment 1: $Z=1.78, N=6, P=0.075$; treatment 2: $Z=0.31, \quad N=6, P=0.753$; treatment $3: Z=1.99, \quad N=6, P=0.046$; treatment 4: $Z=0.73, N=6, P=0.463$.

background, respectively (treatments 3 and 4; Fig. 4). No difference was found in treatments 1 (live fish versus filmed fish) and 2 (real background versus filmed background; Fig. 4).

\section{DISCUSSION}

Our results strongly suggest that individual $S$. pavo do not perceive video images as conspecifics. Both males and females spent more time near live than videotaped conspecific males and attacked or courted only live males. It could be argued that these negative results were due to deficiencies in our experimental set-up (e.g. poor quality of the video stimuli). However, the video playback technique produced the predicted results with $P$. formosa. No differences in the reaction to live and video stimuli were recorded suggesting that, in contrast to other species (e.g. Neolamprologus brichardi: Balshine-Earn \& Lotem 1998),

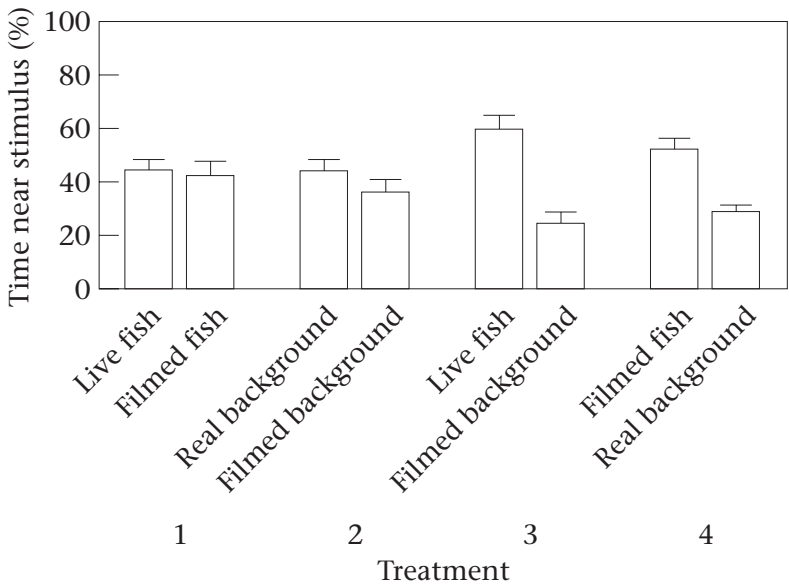

Figure 4. Mean $+S E$ time spent by $P$. formosa females near each stimulus. Treatment 1: $Z=0.56, N=20, P=0.575$; treatment 2: $Z=1.19, N=20, P=0.232$; treatment 3: $Z=3.21, N=20, P=0.001$; treatment $4: Z=2.94, N=20, P=0.003$.

female $P$. formosa react as strongly to video images of a $P$. mexicana male as to a live animal. Previous studies in this species had already shown a positive reaction of females to video images (Körner et al. 1999; Landmann et al. 1999). Landmann et al. (1999) provided evidence that time spent near the stimulus was not a consequence of a reaction to movement on the screen but that the video stimulus was indeed informative for this species. It thus seems that the same set-up may produce very different results depending on the species studied. The fact that $P$. formosa females still respond to video images when tested in sea water also rules out the quality of the transmission medium as an explanation for failure in using video playbacks with marine species.

Three recent reviews have summarized the main concerns that need to be addressed when using the video playback technique (D'Eath 1998; Fleishman et al. 1998; Oliveira et al., in press). The absence of depth cues in video images, the species' spatial and temporal resolution, the distance at which the stimulus is presented, background contrast and incorrect colour reproduction by video systems to the majority of nonhuman observers (Dawkins \& Woodington 1997; D'Eath 1998; Fleishman et al. 1998; Fleishman \& Endler, in press; Oliveira et al., in press) might explain the negative reaction of $S$. pavo to video playbacks. The issue of temporal resolution has been addressed by Fleishman \& Endler (in press), clarifying the erroneous assumption that the refresh rate of the display device has to be higher than the species' critical frequency of fusion (CFF) in order to create an illusion of smooth motion. The authors argued that even if the species studied has a CFF above the refresh rate of the display device, that is unlikely to destroy the perception of motion on the screen (for details see Fleishman $\&$ Endler, in press). Here we interpret our results addressing problems related to colour reproduction, depth perception and spatial resolution. 


\section{Colour}

As video monitors have been developed for the human visual system, differences in the number of photoreceptor classes and in the spectral sensitivities of visual pigments between humans and the majority of other animals may lead to the incorrect interpretation of colours displayed in video monitors (for details see D'Eath 1998; Fleishman et al. 1998; Fleishman \& Endler, in press). Zaunreiter (1990) described the retina of $S$. pavo as consisting of rods, single and double cones with cones arranged in a regular mosaic: four double cones form a square with a single cone at the centre. However, as far as we know no data are available on the spectral sensitivities of photoreceptors in $S$. pavo. The retina of $P$. formosa has rods, single, double and twin cones (K. E. Körner \& E. R. Loew, unpublished data). These authors also found four types of cones with different maximum absorbances: ultraviolet cones $(352 \mathrm{~nm})$, violet cones $(404 \mathrm{~nm})$, blue cones $(463 \mathrm{~nm})$ and long-wavelength cones (range 529-598 nm). If $P$. mexicana males reflect ultraviolet wavelengths, those colours would not be reproduced on the video screen. Furthermore, as the absorbance maximum of $P$. formosa cones differs from human cones $(435,534,560 \mathrm{~nm}$, Boynton 1979) colours must be perceived as different. Thus, females of $P$. formosa are most probably relying on other cues such as shape or movement pattern to identify the sperm donor males. Colours reproduced by video monitors may also be perceived differently by $S$. pavo but, for this species, they may be fundamental for conspecific recognition.

\section{Depth}

Video monitors reproduce images in a two-dimensional plane. It is likely that the majority of nonhuman animals are unable to extrapolate a third dimension from video images (D'Eath 1998; Zeil, in press, but see Forkman 1997). The lack of certain depth cues in video images such as those derived from motion parallax, binocular stereopsis and changes in focusing (Zeil, in press) may lead to an incorrect interpretation of the stimulus. For example, a fish viewing images of a conspecific swimming back and forth in a tank might interpret these as the fish increasing in size as it approaches the camera and decreasing as it swims away. In our study this applied particularly to $P$. formosa females, as video images presented as stimuli consisted typically of a $P$. mexicana male swimming back and forth in the tank. In contrast, male and female $S$. pavo were presented with images of a conspecific male typically inside the nest with its head out for the whole trial.

\section{Visual Acuity}

The visual acuity (or spatial resolution) of an animal is defined as the reciprocal of the angle formed at the eye by two objects that the animal can just recognize as being separate (Douglas \& Hawryshyn 1990). Animals with high spatial resolution presented with video images at close range might be able to discriminate between the individual pixels that compose an image (Oliveira et al., in press). Image pixelation may destroy information contained in the stimuli. As far as we know no data are available on the visual acuity of the species we studied. Differences in the visual acuity of these species could contribute to their opposite reaction to video images.

Vision seems to be particularly important for intertidal fish species such as $S$. pavo, owing to the destruction of information in other stimuli categories (e.g. lateral line, taste) by turbulence (Kotrschal 1999). Intertidal species, including blennies, have a well-developed optic tectum suggesting a broad use of the sense of vision with high resolving power, colour vision and easy detection of movements (Kotrschal 1999). Thus, images reproduced by video systems may be, in several aspects, a poor representation of natural scenes for such a highly visual species.

Further studies on the visual system of these species, namely the determination of the number of photoreceptor classes and the characterization of their spectral sensitivities, the species' spatial and temporal resolution, and the characterization of the light environment in which both species inhabit are essential for designing an appropriate video playback methodology.

\section{Acknowledgments}

We thank the Ria Formosa Nature Park, especially its director Dr Luís Fonseca, for providing essential logistical and technical support. Travel support was provided by an ICCTI/INIDA Portuguese/German collaboration grant (project 423/DAAD). During this study D.M.G. was funded by a Praxis XXI Ph.D. grant (BD/13436/97). I.S. was supported by the DFG. We are grateful to Dr Enrico Ferrero and an anonymous referee for their valuable comments on the manuscript.

\section{References}

Abel, E. F. 1993. Coloration phenomena of Mediterranean blennies (Pisces, Blenniidae). Marine Ecology (PSZNI), 14, 291-312.

Almada, V. C., Gonçalves, E. J., Santos, A. J. \& Baptista, C. 1994. Breeding ecology and nest aggregations in a population of Salaria pavo (Pisces: Blenniidae) in an area where nest sites are very scarce. Journal of Fish Biology, 45, 819-830.

Almada, V. C., Gonçalves, E. J., Oliveira, R. F. \& Santos, A. J. 1995. Courting females: ecological constraints affect sex roles in a natural population of the blenniid fish, Salaria pavo. Animal Behaviour, 49, 1125-1127.

Balshine-Earn, S. \& Lotem, A. 1998. Individual recognition in a cooperatively breeding cichlid: evidence from video playback experiments. Behaviour, 135, 369-386.

Boynton, R. M. 1979. Human Color Vision. New York: Holt, Reinhart $\&$ Winston.

Clark, D. L. \& Uetz, G. W. 1990. Video image recognition by the jumping spider, Maevia inclemens (Araneae: Salticidae). Animal Behaviour, 40, 884-890.

Dawkins, M. S. \& Woodington, A. 1997. Distance and the presentation of visual stimuli to birds. Animal Behaviour, 54, 1019-1025. 
D'Eath, R. B. 1998. Can video images imitate real stimuli in animal behaviour experiments? Biological Reviews, 73, 267-292.

D'Eath, R. B. \& Dawkins, M. S. 1996. Laying hens do not discriminate between video images of conspecifics. Animal Behaviour, 52, 903-912.

Douglas, R. H. \& Hawryshyn, C. W. 1990. Behavioural studies of fish vision: an analysis of visual capabilities. In: The Visual System of Fish (Ed. by R. H. Douglas \& M. B. A. Djamgoz), pp. 373-418. London: Chapman \& Hall.

Evans, C. S. \& Marler, P. 1992. Female appearance as a factor in the responsiveness of male chickens during anti-predator behaviour and courtship. Animal Behaviour, 43, 137-145.

Falls, J. B. 1991. Playback. A historical perspective. In: Playback and Studies of Animal Communication (Ed. by P. K. McGregor), pp. 11-33. New York: Plenum.

Fishelson, L. 1963. Observations on littoral fishes of Israel. I. Behaviour of Blennius pavo Risso (Teleostei: Blenniidae). Israel Journal of Zoology, 12, 67-80.

Fleishman, L. J. \& Endler, J. A. In press. Some comments on visual perception and the use of video playback in animal behavior studies. Acta Ethologica.

Fleishman, L. J., McClintock, W. J., D'Eath, R. B., Brainard, D. H. \& Endler, J. A. 1998. Colour perception and the use of video playback experiments in animal behaviour. Animal Behaviour, 56, 1035-1040.

Forkman, B. 1997. Hens see depth in a two-dimensional picture. Advances in Ethology, 32, 91.

Gonçalves, E. J., Almada, V. C., Oliveira, R. F. \& Santos, A. J. 1996. Female mimicry as a mating tactic in males of the blenniid fish Salaria pavo. Journal of the Marine Biological Association of the United Kingdom, 76, 529-538.

Kodric-Brown, A. 1992. Male dominance can enhance mating success in guppies. Animal Behaviour, 44, 165-167.

Kodric-Brown, A. \& Nicoletto, P. F. 1997. Repeatability of female choice in the guppy: response to live and videotaped males. Animal Behaviour, 54, 369-376.

Körner, K. \& Parzefall, J. 1997. Mate choice in a cave-living and an epigean population of Poecilia mexicana: a study using computer animated video images. Advances in Ethology, 32, 206.

Körner, K. E., Lütjens, O., Parzefall, J. \& Schlupp, I. 1999. The role of experience in mating preferences of the unisexual Amazon molly. Behaviour, 136, 257-268.

Kotrschal, K. 1999. Sensory systems. In: Intertidal Fishes: Life in Two Worlds (Ed. by M. H. Horn, K. L. M. Martin \& M. A. Chotkowski), pp. 126-142. San Diego: Academic Press.

Landmann, K., Parzefall, J. \& Schlupp, I. 1999. A sexual preference in the Amazon molly, Poecilia formosa. Environmental Biology of Fishes, 56, 325-331.

Laumen, J., Pern, U. \& Blüm, V. 1974. Investigations on the function and hormonal regulations of the anal appendices in Blennius pavo. Journal of Experimental Zoology, 190, 47-56.

Macedonia, J. M. \& Stamps, J. A. 1994. Species recognition in Anolis grahami (Sauria, Iguanidae): evidence from responses to video playbacks of conspecific and heterospecific displays. Ethology, 98, 246-264.

McGregor, P. K., Catchpole, C. K., Dabelsteen, T., Falls, J. B., Fusani, L., Gerhardt, H. C., Gilbert, F., Horn, A. G., Klump, G. M., Kroodsma, D. E., Lambrechts, M. M., McComb, K. E., Nelson, D. A., Pepperberg, I. M., Ratcliffe, L., Searcy, W. A. \& Weary, D. M. 1991. Design of playback experiments: the Thornbridge Hall NATO ARW consensus. In: Playback and Studies of Animal Communication (Ed. by P. K. McGregor), pp. 11-33. New York: Plenum.

Myrberg, A. A. \& Riggio, R. J. 1985. Acoustically mediated individual recognition by a coral reef fish (Pomacentrus partitus). Animal Behaviour, 33, 411-416.

Myrberg, A. A. Jr, Mohler, M. \& Catala, J. D. 1986. Sound production by males of a coral reef fish (Pomacentrus partitus). Animal Behaviour, 34, 913-923.

Oliveira, R. F., Rosenthal, G. G., Schlupp, I., McGregor, P., Cuthill, I., Endler, J., Fleishman, L., Zeil, J., Barata, E., Burford, F., Goncalves, D. M., Healey, M., Jakobson, S., Jennions, M., Körner, K., Lindstrom, L., Peake, T., Pilastro, A., Pope, D., Roberts, S., Rowe, C., Smith, J. \& Waas, J. In press. Considerations on the use of video playbacks as visual stimuli: the Lisbon workshop consensus. Acta Ethologica.

Papaconstantinou, C. A. 1979. Secondary sex characters of Blennioid fishes (Pisces: Blenniidae). Thalassographica, 1, 57-75.

Patzner, R. A. \& Seiwald, M. 1987. The reproduction of Blennius pavo. VII. Secondary sexual organs and accessory glands of the testis during the reproductive cycle. Proceedings of the $V$ Congress of European Ichthyologists, Stockholm 1985, 293-298.

Patzner, R. A., Seiwald, M., Adlgasser, M. \& Kaurin, G. 1986. The reproduction of Blennius pavo. V. Reproductive behaviour in natural environment. Zoologischer Anzeiger, 216, 338-350.

Patterson-Kane, E., Nicol, C. J., Foster, T. M. \& Temple, W. 1997. Limited perception of video images by domestic hens. Animal Behaviour, 53, 951-963.

Pepperberg, I. M. 1994. Vocal learning in grey parrots (Psittacus erithacus) effects of social interaction, reference and context. Auk, 111, 300-313.

Pepperberg, I. M., Naughton, J. R. \& Banta, P. A. 1998. Allospecific vocal learning by grey parrots (Psittacus erithacus): a failure of videotaped instructions under certain conditions. Behavioural Processes, 42, 139-158.

Rosenthal, G. G., Evans, C. S. \& Miller, W. L. 1996. Female preference for a dynamic trait in the green swordtail, Xiphophorus helleri. Animal Behaviour, 51, 811-820.

Ruchon, F., Laugier, T. \& Quignard, J. P. 1995. Alternative male reproductive strategies in the peacock blenny. Journal of Fish Biology, 47, 826-840.

Ryan, C. M. \& Lea, S. E. G. 1994. Images of conspecifics as categories to be discriminated by pigeons and chickens: slides, videotapes, stuffed birds and live birds. Behavioural Processes, 33, 155-176.

Schlupp, I., Parzefall, J. \& Schartl, M. 1991. Male mate choice in mixed bisexual/unisexual breeding complexes of Poecilia (Teleostei: Poeciliidae). Ethology, 88, 215-222.

Schlupp, I., Nanda, I., Doebler, M., Lamatsch, D. K., Epplen, J. T., Parzefall, J., Schmid, M. \& Schartl, M. 1998. Dispensable and indispensable genes in an ameiotic fish, the Amazon molly Poecilia formosa. Cytogenetics and Cell Genetics, 80, 193-198.

Zaunreiter, M. 1990. Zwischenartliche Differenzierung des Optischen Systems bei Mediterranen Blenniiden (Blenniidae, Perciformes, Teleostei). Ph.D. thesis, University of Salzburg.

Zeeck, E. \& Ide, V. 1996. The role of sex pheromones in the reproductive behaviour of Blennius pavo (Risso). In: Fish Pheromones: Origins and Mode of Action (Ed. by A. V. M. Canário \& D. Power), pp. 33-38. Faro: University of Algarve.

Zeil, J. In press. Depth cues, behavioural context, and natural illumination: some potential limitations of video-replay techniques. Acta Ethologica. 